\title{
Innovation of Neuropsychopharmacological Experimental Methods to Investigate Attention in Human Participants and Its Validation by Randomized Double Blind Placebo Controlled Clinical Trial
}

\author{
Md. Sahab Uddin*, Abdullah Al Mamun, Md. Asaduzzaman \\ Department of Pharmacy, Southeast University, Dhaka, Bangladesh \\ Email: *msu-neuropharma@hotmail.com, "msu_neuropharma@hotmail.com
}

Received 15 March 2016; accepted 16 July 2016; published 19 July 2016

Copyright (C) 2016 by authors and Scientific Research Publishing Inc.

This work is licensed under the Creative Commons Attribution International License (CC BY). http://creativecommons.org/licenses/by/4.0/

\begin{abstract}
In terms of advancement of life to meet the challenges new method for neuropsychopharmacological research are continually developing to ensure superior safety, accuracy, efficacy, precision etc. In this experiment, we suggested and validated two neuropsychopharmacological testing methods, these are Numeral Finding (NF) and Typo Revealing (TR) tests for the determination of attention in healthy aged human participants. The objective of this experiment was to generate more effective testing methods for the assessment of attention in human. The rationality of the aforementioned methods was checked by a randomized double blind placebo controlled clinical trial for the period of 21 days among healthy aged human participants. The experiment was conducted at Gazipur Sadar, Gazipur-1703, Dhaka, Bangladesh between the period of December 2015 and March 2016. The experiment center was the Department of Pharmacy, Southeast University, Dhaka-1213, Bangladesh. In this experiment, 60 healthy male participants between the age ranges of 40 to 50 years old were selected and randomly divided by simple randomization process into 3 groups with 20 participants in each. Ginkgo biloba standardized extract's capsule (Giloba ${ }^{\circledR}$ and Kobi ${ }^{\circledR}$ ) was used as a standard and as a placebo control psyllium seed husk (i.e., seed of the Plantago ovata) was used after filling in the hard gelatin capsule shell (size 0). Group 1 was treated with Giloba ${ }^{\circledR}$ in which each capsule contained $120 \mathrm{mg}$ Ginkgo biloba standardized extract (GBG) and group 2 was treated with Kobi ${ }^{\circledR}$ in which each capsule contained $60 \mathrm{mg}$ Ginkgo biloba standardized extract (GBK). The treatment procedure for group 3 was psyllium seed husk's capsule that served as placebo control (PC). Throughout the experiment each capsule was administered 3 times daily.
\end{abstract}

"Corresponding author.

How to cite this paper: Uddin, Md.S., et al. (2016) Innovation of Neuropsychopharmacological Experimental Methods to Investigate Attention in Human Participants and Its Validation by Randomized Double Blind Placebo Controlled Clinical Trial. Journal of Behavioral and Brain Science, 6, 280-293. http://dx.doi.org/10.4236/jbbs.2016.67028 
Treatment with Ginkgo biloba standardized extracts for successive days markedly increased the attention of the participants with respect to PC group. In the NF test, administration of GBG and GBK extracts significantly $(P<0.05, P<0.01 ; P<0.01)$ increased the attention of the participants on $14^{\text {th }}$ and $21^{\text {st }}$ day as compared to that of PC group. For TR test treatment with GBG and GBK extracts markedly $(P<0.01 ; P<0.001, P<0.01)$ increased the attention of the participants on $14^{\text {th }}$ and $21^{\text {st }}$ day with respect to $\mathrm{PC}$ group. The existing experiment proved that NF and TR tests undoubtedly revealed the attention enhancing activity of the Ginkgo biloba standardized extracts in healthy aged human participants. Consequently, the recommended newly emerging methods can be used for the assessment of attention in human and will create a miracle in the domain of neuroscience.

\section{Keywords}

Neuropsychopharmacology, Numeral Finding Test, Typo Revealing Test, Attention, Clinical Trial

\section{Introduction}

The human brain is the main organ of the human central nervous system (CNS) that regulates all functions. The extraordinary human abilities depend on several factors in which attention is vital [1]. Attention is the process of concentrating on a specific aspect of information to accomplish the chosen task by filtering distracting information [2]. The attention power of human varies from man to man. Every discovery and invention is the results of extensive attention of not only complex, but also simplex things present in our surroundings [3]. Several studies have exposed that in Einstein's brain regions involved with numerical and spatial processing are larger than regions involved in speech and language. Further studies have suggested an increased number of glial cells in Einstein's brain [4]. The performance of any work depends on attention. The expression of attention may vary in strength from a low intensity to a high intensity as well as may vary in duration short to sustain [5].

Attention is the precursor to all other neurological/cognitive functions [6]. In the course of attention multiple stimuli from the outside environment bombard body's specialized sensory receptors and the brain performed searching to select only desire subject of interest [7]. During searching brain frequently shifts its focus between external events and internal memories and interests. In order to maintain and upgrade memory, this sifting of internal and external events is mandatory [8]. Research suggests that brain cell cannot process all stimuli, it only processes those stimuli that are most potent. In addition to this, automatically brain cell focuses on that information that contains high contrast and or emotional intensity [9].

Attention deficit hyperactivity disorder (ADHD) is a neurobehavioral disorder involving behavior dysfunctions and cognitive impairments. ADHD is characterized by persistent and chronic inattention and or hyperactivity-impulsivity that interfere with the functioning or development of the brain [10]. This disease is most common among in childhood and can continue through adolescence and adulthood. Worldwide the prevalence of ADHD is about 7\% and boys are four times at risk than girls [11] [12]. Attentional deficits are frequently seen in isolation as the presenting sign and symptom of neurodegenerative disease, manifest as mild cognitive impairment (MCI) [13]. For geriatric people persistent ADHD leads to neurodegenerative diseases. In fact, alteration of neuroanatomic assemblies or neurochemical function and or pathway is the causative agent for the development and propagation of de novo late life neurodegenerative disease such as Alzheimer's disease (AD), Parkinson's disease (PD), Lewy body dementia (LBD), frontotemporal dementia (FTD) etc. [14].

Neuropsychological tests are linked to the brain structures or pathway into brain functions [15]. In order to measure memory, intelligence, attention, cognitive, visuospatial, executive function etc. in patients with neurological disorders or psychological disorders or neuropsychological disorders, various types of neuropsychological tests is effective [16]. In addition to this, in the research of human brain and diagnosis of neuropsychological disorders, they are widely used [17]. But currently used most neuropsychological tests are based on traditional psychometric theory [18]. Therefore, the intention of this experiment is to display and verify two neuropsychopharmacological testing methods these are Numeral Finding (NF) and Typo Revealing (TR) tests to resolve attention in normal aged human participants. 


\section{Objectives}

The specific objectives of NF and TR tests are offered below:

1. To measure attention deficits in patients with neurological and or psychological or neuropsychological disorders NF test is efficient.

2. To determine attention problems in patients with neurological and or psychological or neuropsychological disorders TR test is operative.

3. To confirm the attention enhancing capacity of unknown medicinal plants/drugs in human NF and TR tests is efficient.

4. To check the attention power of human NF and TR tests is competent.

5. To endorse the presence or absence of attention deficits of patient's with neurological and or psychological or neuropsychological disorders NF and TR tests is impressive.

6. To confirm the effect of established drugs in the attention of human NF and TR tests is effective.

\section{Materials and Methods}

\subsection{Study Design}

The study protocol of the randomized double blind placebo controlled clinical trial of this experiment is specified in Figure 1. Simple randomization process was used to randomize the participants. The place of the experiment was Gazipur Sadar, Gazipur-1703, Dhaka, Bangladesh. The experiment center of this clinical trial was the Department of Pharmacy, Southeast University, Dhaka-1213, Bangladesh. The protocol of the experiment was approved by the ethics committee of the Department of Pharmacy, Southeast University, Dhaka-1213, Bangladesh.

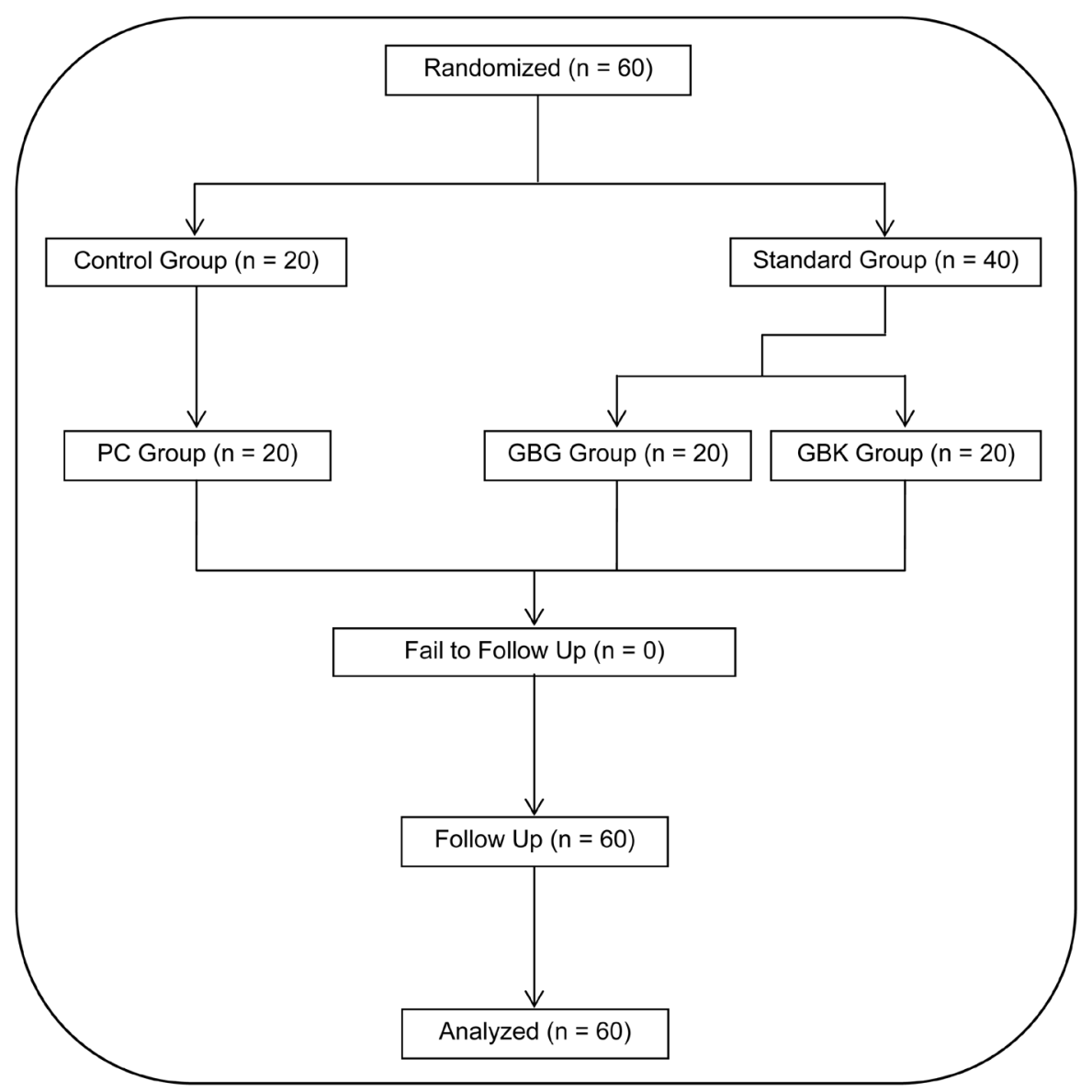

Figure 1. Blueprint presenting the movement of the participants through the clinical trial. 


\subsection{Study Population}

In this experiment healthy 60 male participants between the ages of 40 to 50 years old were arbitrarily selected and till last of the experiment all the participants attended. Table 1 represents the demographic information of the participants. Since it is not possible as well as unethical to create attention deficits in human to validate the proposed methods, as a consequence healthy aged participants were chosen. In addition to this, it is not likely to choose participants with attention problems (i.e., ADHD, $\mathrm{AD}$ ), but able to partake in this experiment. Oxidative stress plays a major role in the aging process and intensely related to it. Many studies have suggested that increased oxidative stress has been implicated in the genesis and propagation of many disorders like neurological disorders, neurodegenerative disease, dementia, cognitive impairment etc. In fact aged people are more susceptible to oxidative stress than younger one and confirmed by several studies [19]-[21]. Before selection of the participants they were subjected to a comprehensive health related questions to estimate the health status. Prior to the experiment, from each participant written informed consent was taken.

\section{Inclusion and Exclusion Criteria}

In this experiment before selection of the participants following conditions were considered:

1. Devoid of any neurological disorders at previous times.

2. Devoid of any psychological disorders at preceding times.

3. Devoid of drug addiction.

4. Devoid of any severe illness within the earlier 3 months.

5. Deprived of cardiovascular, renal, hepatic, eye disease and diabetes.

6. Participants who miss any doses for more than a day, were intended to vanish from the experiment.

Furthermore, prior to selection a number of factors, including lifestyle, socioeconomic condition, personal issues, work profile, work stress, food habits, medication history, intelligence etc. of the participants were inspected. The educational background and body surface area of the participants were also considered during selection of the participants.

\subsection{Standard Drugs}

Ginkgo biloba is a well-known established natural nootropic herbal drug [22]. In this experiment Ginkgo biloba standardized extract was used as a standard drug to examine the efficacy of the proposed testing methods. Ginkgo biloba leaf extracts contain several active constituents including flavonoids, terpenoids and organic acids. The majority of Ginkgo biloba leaf extract is standardized to contain $24 \%$ flavone glycosides (primarily com-

Table 1. Demographic information of the participants.

\begin{tabular}{|c|c|c|}
\hline Variable & $\mathbf{n}$ & $\%$ \\
\hline \multicolumn{3}{|l|}{ Sex } \\
\hline Male & 60 & 100 \\
\hline \multicolumn{3}{|l|}{ Age } \\
\hline $40-45$ & 39 & 65.00 \\
\hline $46-50$ & 21 & 35.00 \\
\hline \multicolumn{3}{|l|}{ Education Level } \\
\hline$<\mathrm{SSC}$ & 8 & 13.33 \\
\hline SSC & 29 & 48.33 \\
\hline HSC & 13 & 21.67 \\
\hline Degree (Pass) & 10 & 16.67 \\
\hline \multicolumn{3}{|l|}{ Occupation } \\
\hline Office Worker & 22 & 36.67 \\
\hline Business & 17 & 28.33 \\
\hline Teacher & 15 & 25.00 \\
\hline Others & 6 & 10.00 \\
\hline \multicolumn{3}{|l|}{ Residential Status } \\
\hline Residential & 46 & 76.67 \\
\hline Nonresidential & 14 & 23.33 \\
\hline
\end{tabular}

where, $\mathrm{SSC}=$ Secondary school certificate, $\mathrm{HSC}=$ Higher secondary certificate, Degree $($ Pass $)=$ This is considered to be a pass but without the honours. 
posed of quercetin, kaempferol and isorhamnetin) and $6 \%$ terpene lactones $(2.8 \%$ to $3.4 \%$ ginkgolides $\mathrm{A}$, $\mathrm{B}$, $\mathrm{C}$ and $2.6 \%$ to $3.2 \%$ bilobalide). Other constituents include proanthocyanadins, glucose, rhamnose, organic acids (hydroxykinurenic, kynurenic, protocatechic, vanillic, shikimic), D-glucaric acid and ginkgolic acid and related alkylphenols [23]-[25]. Several studies recommended that Ginkgo biloba is effective for the treatment of age-related memory impairment, dementia, cognitive function, peripheral vascular disease etc. [26] [27].

Two widely used commercially available preparations of Ginkgo biloba standardized extract in Bangladesh are Giloba ${ }^{\circledR}$ and $\mathrm{Kobi}^{\circledR}$. Giloba ${ }^{\circledR}$ and $\mathrm{Kobi}^{\circledR}$ are available as capsule manufactured by SQUARE Herbal \& Nutraceuticals Ltd. and Hamdard Laboratories (WAQF) Bangladesh respectively. For this study Giloba ${ }^{\circledR}$ and Kobi ${ }^{\circledR}$ were purchased from retail pharmacies of Dhaka city in Bangladesh.

\subsection{Treatment}

In this experiment as standard drugs Ginkgo biloba standardized extracts (Giloba ${ }^{\circledR}$ and Kobi ${ }^{\circledR}$ ) were administered to participants for 21 days to validate the efficacy of the proposed testing methods. The dosage form of the Giloba $^{\circledR}$ is capsule and each capsule contains $120 \mathrm{mg}$ Ginkgo biloba standardized extract. On the other hand, $\mathrm{Kobi}^{\circledR}$ is also available as capsule that contains $60 \mathrm{mg}$ Ginkgo biloba standardized extract per capsule. Psyllium seed husk (i.e., seed of the Plantago ovata) was filled in the empty hard gelatin capsule shell (size 0 ) to prepare the capsule and used as placebo control (PC). The manufacturing process of the capsules was completed in the ISO and GMP certified Modern Pharmaceuticals Ltd., Dhaka, Bangladesh. Psyllium seed husk has no nootropic activity and non-toxic that's why it was chosen as placebo control. After consultation with physician and literature searches the doses of these standard drugs and duration of the experiment were adjusted [23] [24] [28] [29]. Allopathic drugs were avoided in this experiment owing to the risk of excessive cholinergic activity as well as adverse effects in the participants since they were healthy aged. In addition to this, a number of studies of herbal drugs suggested that they are safer than allopathic drugs [30]-[33]. The treatment period of this clinical trial was 21 days.

\subsection{Experimental Design}

The participants were randomized into three groups with 20 participants in each as follows:

Group 1: This group received Ginkgo biloba standardized extract (120 mg/capsule), 1 capsule 3 times daily for 21 days (GBG).

Group 2: This group received Ginkgo biloba standardized extract (60 mg/capsule), 1 capsule 3 times daily for 21 days (GBK).

Group 3: This group received psyllium seed husk (hard gelatin capsule shell size 0) as placebo control, 1 capsule 3 times daily for 21 days (PC).

The participants were suggested to take capsule before 30 minutes of meal with plenty of water for better absorption. The chance of underdose and overdose owing to the sub-thepareutic and excessive concentration of the drugs were removed by recommended them to take capsule after each 8 hour interval for 3 times daily. Throughout the experiment normal diet was proposed to take and health status of the participants was checked after each 3 day's intermission with the help of the physician. All participants were instructed to call the hotline of the experiment if they experienced any adverse effects during and after the experiment. To remove the chance of post treatment complications, the participants were kept under physician checkup for 7 days after the experiment.

In this experiment NF and TR tests were conducted among participants between the period from 10:00 am to $12: 00 \mathrm{pm}$ on $7^{\text {th }}, 14^{\text {th }}$ and $21^{\text {st }}$ day.

\subsection{Attention Test}

\subsubsection{Numeral Finding Test}

This test is based on finding the wanted numerals among a set of numbers. In this test 100 numbers are placed randomly in a chart that consists of ten columns and ten rows in a printed paper and given to the subject offered in Figure 2. The numbers must be consisted of double digit (i.e., 10 to 99). From 1 to 100 if single digits (i.e., 1 to 9) and triple digit (i.e., 100) are not considered there are 90 double digits. When these double digits are placed unsystematically in the chart to make 100 numbers, 10 numerals must be added that will serve as wanted numeral (Figure 3). These wanted numerals must be the repetition of at least three numbers. In Figure 3, numeral 14, 50 


\begin{tabular}{|llllllllll|}
\hline 83 & 59 & 38 & 22 & 75 & 93 & 14 & 44 & 27 & 86 \\
\hline 48 & 62 & 71 & 13 & 55 & 89 & 70 & 19 & 52 & 43 \\
\hline 91 & 78 & 34 & 14 & 15 & 98 & 63 & 79 & 26 & 67 \\
\hline 50 & 73 & 95 & 40 & 16 & 57 & 62 & 46 & 31 & 90 \\
\hline 65 & 76 & 29 & 72 & 45 & 81 & 33 & 74 & 62 & 18 \\
\hline 80 & 94 & 21 & 47 & 50 & 36 & 88 & 53 & 92 & 68 \\
\hline 24 & 62 & 99 & 56 & 96 & 14 & 39 & 50 & 17 & 58 \\
\hline 41 & 66 & 50 & 97 & 84 & 37 & 12 & 51 & 30 & 42 \\
\hline 23 & 85 & 64 & 49 & 11 & 60 & 35 & 54 & 14 & 25 \\
69 & 28 & 87 & 20 & 10 & 82 & 62 & 77 & 61 & 32 \\
\hline
\end{tabular}

Figure 2. Numeral finding test by using set of numerals. Randomly placed numerals in a chart on the printed paper given to the subject to find wanted numerals.

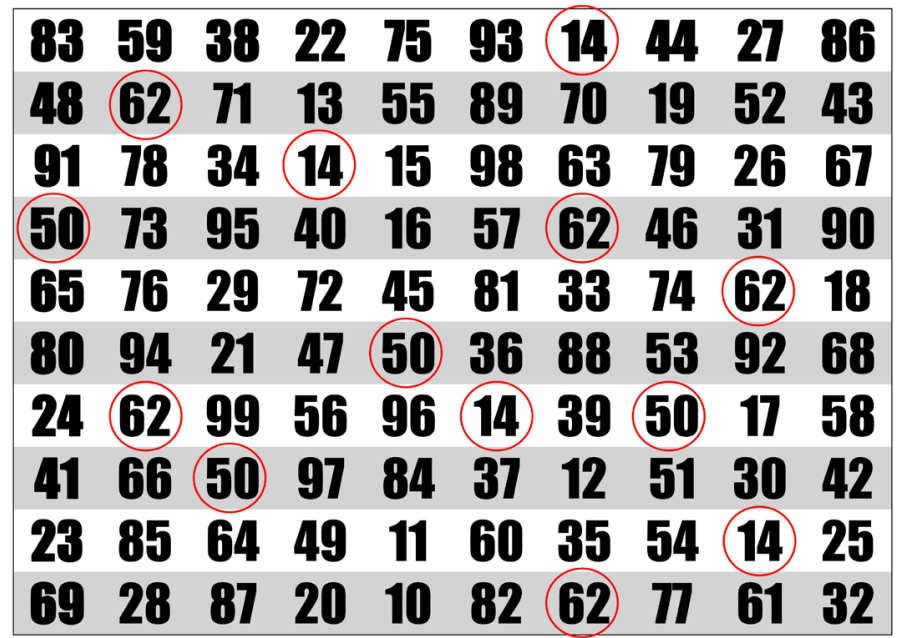

Figure 3. Numeral finding test by using set of numerals. Wanted numerals from the set of numerals [i.e., Figure 2] are marked by red circles.

and 62 is repeated 3, 3 and 4 times respectively to fill 10 wanted numerals. Since these numerals fall between 10 to 99 finally numeral 14,50 and 62 is repeated 4,4 and 5 times respectively. So lastly, there are 13 wanted numerals consist of repetition of 3 numerals. The time taken by subject, to find the wanted number is considered as numeral finding time (NFT). The duration of this test is 180 seconds. The background of the sample might influence the duration of this test. So to select the duration one can perform this test to a number of samples and choose the mean time. Gradual decrease in NFT indicates progress of the attention. The percentage of improved attention (IA) is calculated by using the formula given below:

$$
\% \text { of IA }=\text { TNCWNs } \times 100 / \text { TNPWNs }
$$

where, TNCWNs $=$ Total number of correct wanted numerals identified by the subject, TNPWNs $=$ Total number of presented wanted numerals in the chart. An increase in IA is considered as an index of upgraded attention.

\subsubsection{Typo Revealing Test}

This test is based on detecting the typo from a passage. In this test a standard passage contains 250 words is given to the subject to read carefully at a glance presented in Figure 4. After that intentionally some typological mistakes are incorporated to the passage. This type of mistake may addition of any letter/punctuation (i.e., neu- 
Pharmacy is the science and art concerned with the preparation and standardization of drugs. It is an applied science and a multidisciplinary subject that links health sciences with chemical sciences and aims to ensure the safe and effective use of pharmaceutical drugs. The word pharmacy is derived from its root word pharma which was a term used since the $15^{\text {th }}$ to $17^{\text {th }}$ centuries. However, the original Greek roots from pharmakon means drug or medicine. The pharmacist is an expert in medicines. A pharmacist can be involved in any aspect of the preparation and use of medicines, from the discovery of their active ingredients to their use by patients. Pharmacists also monitor the effects of medicines, both for patient care and for research purposes. Pharmacy, therefore, refers to the profession, which is concerned with the handling of all aspects of chemical substances, referred to as drug or medicine. The pharma often operated through a retail shop which, in addition to ingredients for medicines, sold tobacco and patent medicines. Often the place that did this was called an apothecary and several languages have this as the dominant term, though their practices are more similar to a modern pharmacy, in English the term apothecary would today be seen as outdated or only appropriate if herbal remedies were on offer to a large extent. The field of pharmacy can generally be divided into following primary disciplines: pharmaceutics, medicinal chemistry, pharmacognosy, pharmacology and pharmacy practice. Pharmacoinformatics is another new discipline, for systematic drug discovery and development.

Figure 4. Typo revealing test by using a passage. Standard passage given to the subject to read carefully at a glance.

roon instead of neuron; bra!in instead of brain), deletion of any letter/punctuation (i.e., nerv instead of nerve; Alzheimers disease instead of Alzheimer's disease), substitution of any letter/punctuation (i.e., antiblotics instead of antibiotics; N_acetyl-p-aminophenol instead of N-acetyl-p-aminophenol), inversion of any letter (i.e., sceince instead of science), providing capital letter instead of small letter etc. and given to subject to find the typos existing in Figure 5. The time taken by subject, to find the typo is considered as typo finding time (TFT). The duration of this test is 180 seconds. The duration of this test mainly depends on the characters of the sample and the type of the passage used. Consequently, one can select the duration by providing passage to a number of samples to read carefully and select the mean time. Gradual decrease in TFT indicates improvement of the attention. The percentage of improved attention (IA) is calculated by using the formula given below:

$$
\% \text { of IA }=\text { TNCTs } \times 100 / \text { TNPTs }
$$

where, TNCTs $=$ Total number of correct typos identified by the subject, TNPTs $=$ Total number of presented typos in the passage. An increase in IA is considered as an index of greater attention.

\subsection{Statistical Analysis}

All the results were expressed as mean \pm SEM and analyzed statistically by one-way analysis of variance (ANOVA). Student's t-test was used for the comparison of PC group and various groups. All statistical and graphical analyses were accomplished using SPSS 16.0 (Chicago, IL, USA) and MS Excel 2010 (Roselle, IL, USA). The value of $P<0.05$ was considered as statistically significant with respect to PC group.

\section{Results}

\subsection{Efficacy of the NF Test}

NF test was used to examine the attention based on the finding of wanted numeral. Figure 6 shows the results of NF test measured on $7^{\text {th }}, 14^{\text {th }}$ and $21^{\text {st }}$ day. Treatment with GBG and GBK standardized extracts for successive 
Pharmaci is the science and art concerned with the preparation and standardization of drugs. It is a applied science and a multidisciplinary subject that links health sciences with chemical sciences and alms to ensure the safe and effective use of pharmaceutical drugs. The word pharmacy is derived from its root word pharma which was a term used since the $15($ th $/ 1) 7^{\text {th }}$ centuries. However, the original greek roots from pharnacon means drug or medicine. The pharmacst is an expert in medicines. A pharmacist can be involved in any aspect of the preparation and use of medicines, from the discovery of their active ingredients to their use by patients. Pharmacists also monitor the effects of medicines, both for patient care and for research purposes. Pharmacy therefoer, refers to the profession, which is concerned with the handling of all aspects of chemical substances, referred to as drug or medicine. The phrama often operated through a retail (sop) which, in addition to engredients for medicines, sold tobacco and patent medicines. Often the place that did this was called an apothecary and several languages have this as the dominant term, though their practices are more similar to a modern pharmasy? in English the term apothecary would today be seen as outdated or only appropriate if herdal remedies were on offer to a large extent. The field of pharmacy can generally be divided into following primary disciplines. pharmaceutics, medicinal chemistry, pharmacognosy, pharmadoolgy and pharmacy practice. Pharmacoinformatics is another new discipline, for systematic drug discovery and development.

Figure 5. Typo revealing test by using a passage. Typological mistakes from the standard passage [i.e., Figure 4] are marked by red circles.

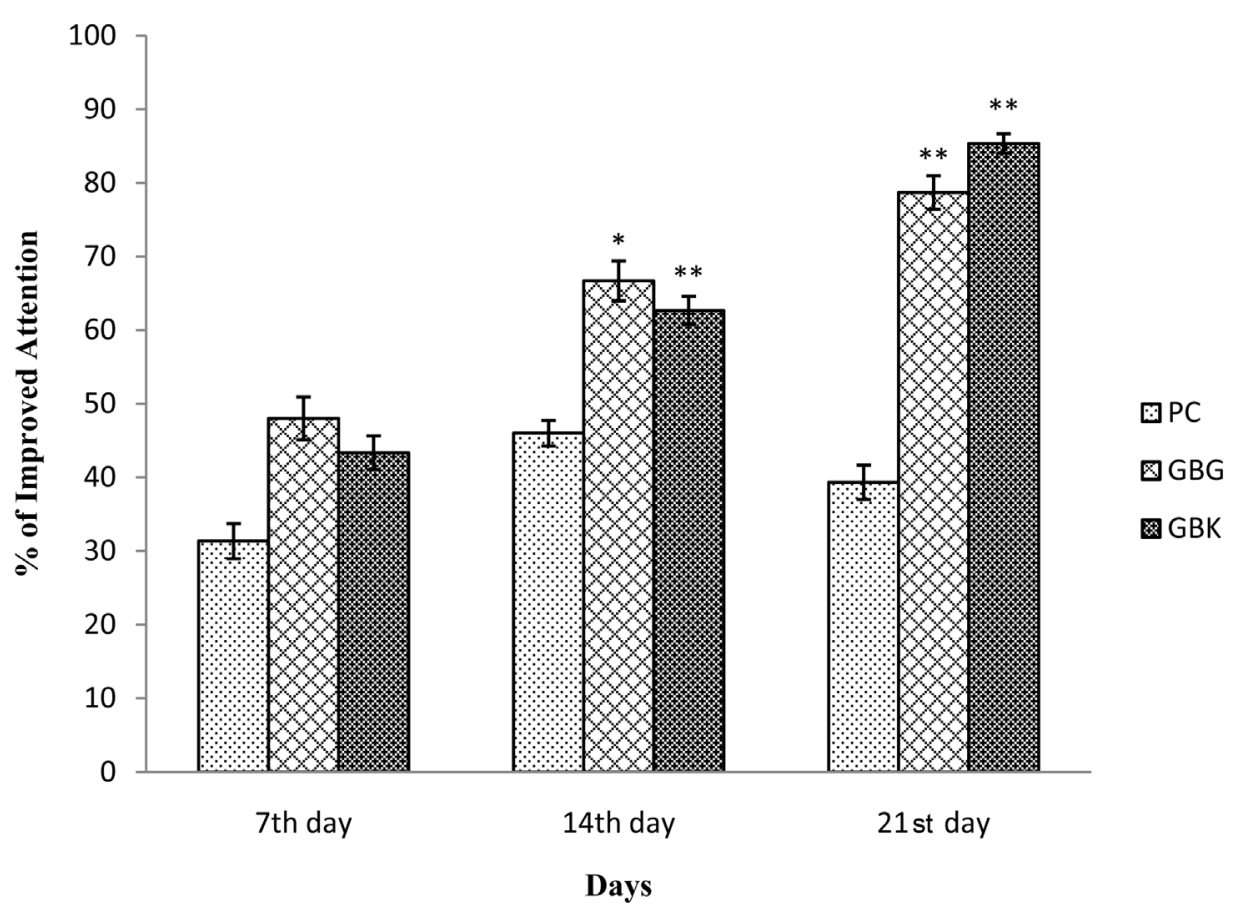

Figure 6. Effect of Ginkgo biloba standardized extract on attention of human participants using NF test. Values were expressed as mean \pm SEM $\left(\mathrm{n}=20\right.$ /group). GBG $=$ Ginkgo biloba standardized extract of Giloba ${ }^{\circledR}, \mathrm{GBK}=$ Ginkgo biloba standardized extract of $\mathrm{Kobi}^{\circledR}, \mathrm{PC}=$ Placebo control. ${ }^{*} P<0.05,{ }^{* *} P<0.01$ significant difference from the PC group. 
days gradually increased the attention of the participants with regard to PC group. The administration of GBG extract significantly $(P<0.05, P<0.01)$ increased the attention of the participants on $14^{\text {th }}$ and $21^{\text {st }}$ day as compared to PC group. Particularly, GBK extract administration markedly $(P<0.01)$ increased the attention of the participant's on $14^{\text {th }}$ and $21^{\text {st }}$ day related to PC group.

\subsection{Efficacy of the TR Test}

The typological error detecting ability of the participants was measured on $7^{\text {th }}, 14^{\text {th }}$ and $21^{\text {st }}$ day displayed in Figure 7. Treatment with GBG and GBK standardized extracts gradually increased the attention of the participants in comparison with PC group. GBG extract treated participants exhibited significantly $(P<0.01)$ increased in attention on $14^{\text {th }}$ and $21^{\text {st }}$ day with respect to PC group. Specifically, administration of GBK extract prominently $(P<0.001, P<0.01)$ increased the attention of the participants on $14^{\text {th }}$ and $21^{\text {st }}$ day as compared to that of $\mathrm{PC}$ group.

\section{Discussion}

The brain is the control center of the human body [34]. Understanding the relationship of brain learning, attention and consciousness is an interesting area of research for neuroscientists. Attention is recognized as one of the three major co-active processes of the working brain [35]. In this experiment we proposed and validated NF and TR tests for the determination of attention in aged human participants.

The brain has many diverse regions, but in case of functioning it operates in a remarkable integrated way [36]. In the attention process brainstem, neurotransmitter, limbic system and neocortex play an important role [37]. The brainstem passively receives incoming sensory information and starts the process of active attention [38]. In the control of arousal and to ignore irrelevant stimuli, reticular formation and locus coeruleus are accountable [39]. Among neurotransmitter, norepinephrine and dopamine are the important neurotransmitter appear to control the processing of attention [40]. Studies suggested that the level of neurotransmitter fluctuations in 90 minute cycles across the 24 hours in the body. In the morning the level of neurotransmitter is higher as a re-

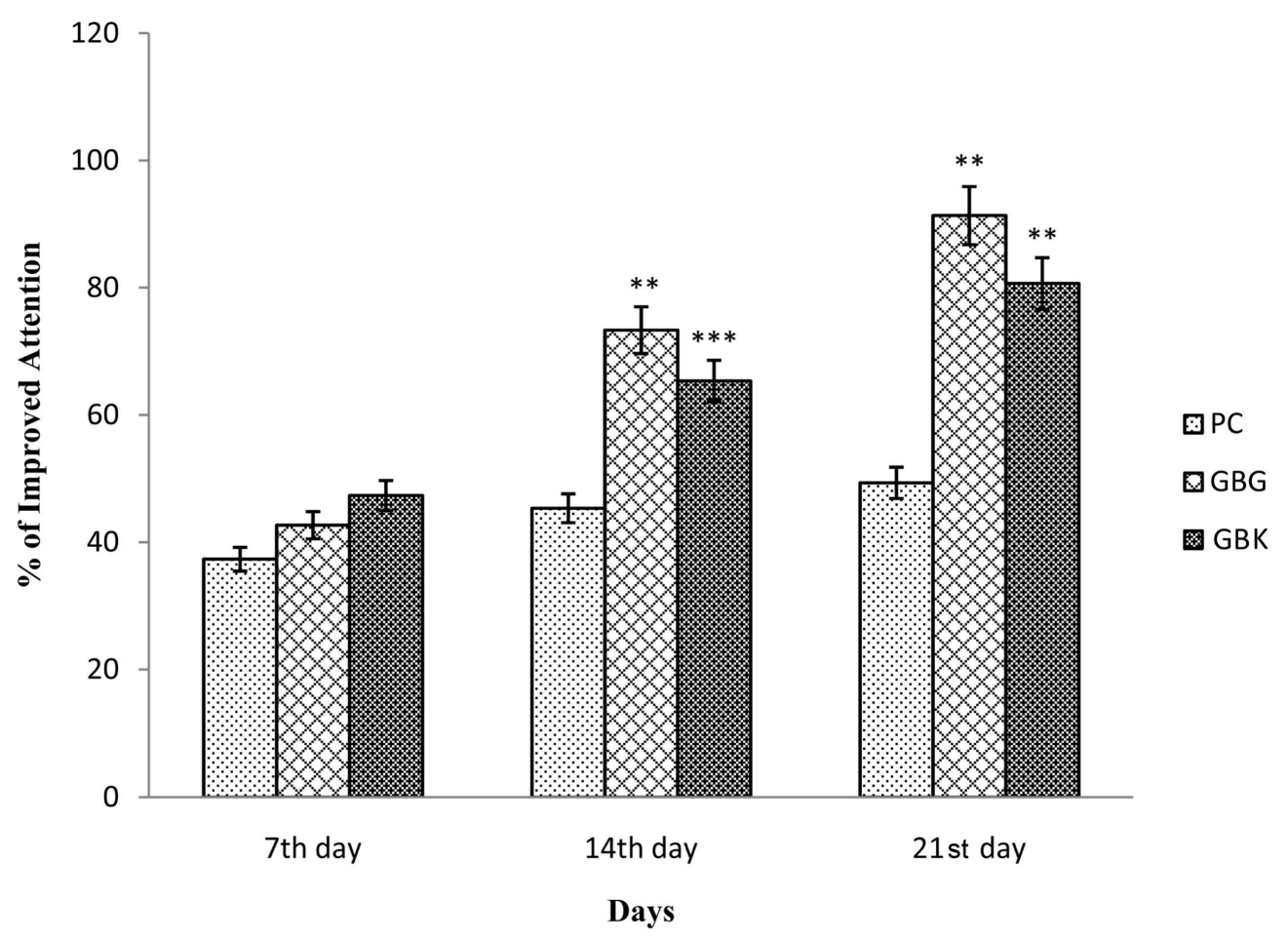

Figure 7. Effect of Ginkgo biloba standardized extract on attention of human participants using TR test. Values were expressed as mean \pm SEM $\left(\mathrm{n}=20\right.$ /group). GBG $=$ Ginkgo biloba standardized extract of Giloba ${ }^{\circledR}, \mathrm{GBK}=$ Ginkgo biloba standardized extract of $\mathrm{Kobi}^{\circledR}, \mathrm{PC}=$ Placebo control. ${ }^{* *} P<0.01,{ }^{* * *} P<0.001$ significant difference from the PC group. 
sult, many people experience a sharp rise in the attention that causes to wake up. During the afternoon the level of neurotransmitters begins to decline and after midnight reaches the lowest levels as a result sleep becomes unavoidable [41]. Optimum level of neurotransmitter is best for proper functioning of attention [40]. The limbic system controls the emotional overtones and motivation for attention [43]. The neocortex is the part of the cerebral cortex that plays a key role in sensory perception, generation of motor commands, spatial reasoning, conscious thought, memory and learning processes etc [44].

To increase the attention span conceptual development is effective by merging related elements into a single unit [45]. Automatically when we see a face we consider it as a single unit, not as individual eye/ear/nose/mouth. But readers, who primarily focus on individual letters and words, have to learn to read entire phrases as single units [46]. In this experiment, we proposed and confirmed NF test for determination of attention that is based on finding wanted numbers among 100 numbers. So in this test there are 100 single units consist of two digits. Among 100 numbers (i.e., 10 - 99), finding of wanted numbers that are repeated several times is tough and in this case more concentration is obligatory for finding and calculation of the each repeating number. That's why NF test is more effective than Trail making test [47] in which the subject is instructed to draw lines sequentially connecting 25 encircled numbers/letters randomly spread in a paper. In addition to this, for NF test with attention concentration is prerequisite owing to the presence of point of focus but for Trail making test only minimal attention is necessary.

The principal attentional activity of human being is the constant conscious selection of a current focus [48]. In case of attention factors like focus and intensity can differ broadly [49]. It will be clarified by comparing between a proofreader and a cursory reader of a magazine article. Initially they cautiously focus to scrutinize individual words and punctuation, then concentrates on the general content. Attention system leads itself in anticipation during try to find such specific information [50]. It increases the response levels of the networks that process that information and it inhibits other networks. That's why, the proofreader scrutinizes a page and marks spelling mistakes, while the cursory reader skims the identical page and marks main content words and phrases [51]. TR test is suggested and validated for the measurement of attention that is based on the finding of typological errors present in the given passage. When readers read the passage to find typos their attention might divide into the time and typos therefore stronger attention and concentration is vital for finding typos. But for Letter Cancellation test the subject is informed to cross out all the target letters among randomly distributed letters in a paper [52]. Consequently, this test is devoid of concentration only minimal attention is required, owing to the aforementioned lacking TR test is superior than Letter Cancellation test.

Fortunately, our attentional system provides us with a short-term memory buffer that allows us to hold a few units of information for several minutes while we determine whether to go on to something else or store the data in our long-term memory. Multitasking is the attempt to execute two or more tasks concurrently. However, the study shows that during multitasking, people make more mistakes and also perform the tasks more slowly [53]. On behalf of the proposed and validated testing methods of this experiment, attention must be divided among all of the component tasks to perform. Consequently, NF and TR tests might effectively detect attention power of the human.

\section{Conclusion}

The brain is the chair of all intellectual abilities. Attention is the brain-based work supported by specific neuronal networks with the help of neurochemicals. In this experiment, we have developed NF and TR tests for the determination of attention in human and validated the effectiveness of the methods by using a randomized double blind placebo controlled clinical trial. The results of this experiment suggest that NF and TR tests are highly efficacious for the measurement of the attention enhancing power of the both Ginkgo biloba standardized extracts in healthy aged human participants. So these testing methods will be effective for various neuropsychopharmacological assessments in human. The notable feature of these aforementioned testing methods is that these can be performed based on the background of the subject, they are not rigid. Therefore, NF and TR tests will make breakthrough in the compass of neuroscience.

\section{Limitations}

Although it was a pilot study the results were statistically significant to bring the impact. However, it would be better if we could perform this experiment among more participants. The nature of participants may also influence the result of the experiment. 


\section{Acknowledgements}

The authors wish to thank the participants of this experiment, our neuropsychopharmacology research team and the Department of Pharmacy, Southeast University, Dhaka-1213, Bangladesh.

\section{Consent to Participate}

The authors took consent from the participants.

\section{Consent for Publication}

The authors took consent for publication.

\section{Ethical Approval}

The study protocol was approved by the ethics committee of the Department of Pharmacy, Southeast University, Dhaka-1213, Bangladesh. This protocol was conducted in accordance with the ethical standards laid down in the 1964 Declaration of Helsinki.

\section{Author's Contributions}

This work was carried out in collaboration between all authors. Author MSU designed the methods, wrote the protocol, managed the analyses of the study and prepared the draft of the manuscript. Author MSU, AAM and MA performed the clinical trial. All the authors read and approved the final manuscript.

\section{Competing Interests}

The authors declare that the research was conducted in the absence of any commercial or financial relationships that could be construed as potential competing interests.

\section{References}

[1] Wilmera, J.B., Germineb, L., Chabrisc, C.F., Chatterjeeb, G., Williamsd, M., Lokene, E., et al. (2010) Human Face Recognition Ability Is Specific and Highly Heritable. Proceedings of the National Academy of Sciences, 107, 5238-5241. http://dx.doi.org/10.1073/pnas.0913053107

[2] McDowd, J.M. (2007) An Overview of Attention: Behavior and Brain. Journal of Neurologic Physical Therapy, 31, 98-103. http://dx.doi.org/10.1097/NPT.0b013e31814d7874

[3] Posner, R. (2009) The Power of Attention. http://humanscience.wikia.com/wiki/The Power of Attention

[4] Fields, R.D. (2009) The Other Brain: From Dementia to Schizophrenia. Simon \& Schuster, New York.

[5] Gillespie, S.M., Rotshtein, P., Wells, L.J., Beech, A.R. and Mitchell, I.J. (2015) Psychopathic Traits Are Associated with Reduced Attention to the Eyes of Emotional Faces among Adult Male Non-Offenders. Frontiers in Human Neuroscience, 9, 1-9. http://dx.doi.org/10.3389/fnhum.2015.00552

[6] Aarnoudse-Moens, C.S.H., Weisglas-Kuperus, N., Duivenvoorden, H.J., van Goudoever, J.B. and Oosterlaan, J. (2013) Executive Function and IQ Predict Mathematical and Attention Problems in Very Preterm Children. PLoS ONE, 8, e55994. http://dx.doi.org/10.1371/journal.pone.0055994

[7] Denckla, M.B. (1996) Biological Correlates of Learning and Attention: What Is Relevant to Learning Disability and Attention-Deficit Hyperactivity Disorder? Journal of Developmental \& Behavioral Pediatrics, 17, 114-119. http://www.ncbi.nlm.nih.gov/pubmed/8727849

[8] Peters, B., Kaiser, J., Rahm, B. and Bledowski, C. (2015) Activity in Human Visual and Parietal Cortex Reveals Object Based Attention in Working Memory. The Journal of Neuroscience, 35, 3360-3369. http://dx.doi.org/10.1523/JNEUROSCI.3795-14.2015

[9] Dwyer, B. (2001) Successful Training Strategies for the Twenty-First Century: Using Recent Research on Learning to Provide Effective Training Strategies. International Journal of Educational Management, 15, 312-318. http://dx.doi.org/10.1108/eum0000000005910

[10] Kolar, D., Keller, A., Golfinopoulos, M., Cumyn, L., Syer, C. and Hechtman, L. (2008) Treatment of Adults with Attention-Deficit/Hyperactivity Disorder. Neuropsychiatric Disease and Treatment, 4, 389-403.

[11] Gephart, H.R. (2003) Attention-Deficit/Hyperactivity Disorder: Diagnosis and Treatment through Adulthood. Primary 
Psychiatry, 10, 27-28.

[12] Lakhan, S.E. and Kirchgessner, A. (2012) Prescription Stimulants in Individuals with and without Attention Deficit Hyperactivity Disorder: Misuse, Cognitive Impact, and Adverse Effects. Brain and Behavior, 2, 661-677. http://dx.doi.org/10.1002/brb3.78

[13] Ivanchak, N., Fletcher, K. and Jicha, G.A. (2012) Attention-Deficit/Hyperactivity Disorder in Older Adults: Prevalence and Possible Connections to Mild Cognitive Impairment. Current Psychiatry Reports, 14, 552-560. http://dx.doi.org/10.1007/s11920-012-0305-8

[14] Bartzokis, G. (2011) Alzheimer's Disease as Homeostatic Responses to Age-Related Myelin Breakdown. Neurobiology of Aging, 32, 1341-1371. http://dx.doi.org/10.1016/j.neurobiolaging.2009.08.007

[15] Arlt, S. (2013) Non-Alzheimer's Disease-Related Memory Impairment and Dementia. Dialogues in Clinical Neuroscience, 15, 465-473.

[16] Roque, D.T., Teixeira, R.A.A., Zachi, E.C. and Ventura, D.F. (2011) The Use of the Cambridge Neuropsychological Test Automated Battery (CANTAB) in Neuropsychological Assessment: Application in Brazilian Research with Control Children and Adults with Neurological Disorders. Psychology \& Neuroscience, 4, 255-265. http://dx.doi.org/10.3922/j.psns.2011.2.011

[17] Burhan, A.M., Marlatt, N.M., Palaniyappan, L., Anazodo, U.C. and Prato, F.S. (2015) Role of Hybrid Brain Imaging in Neuropsychiatric Disorders. Diagnostics, 5, 577-614. http://dx.doi.org/10.3390/diagnostics5040577

[18] Dickinson, D. and Gold, J.M. (2008) Less Unique Variance than Meets the Eye: Overlap among Traditional Neuropsychological Dimensions in Schizophrenia. Schizophrenia Bulletin, 34, 423-434. http://dx.doi.org/10.1093/schbul/sbm092

[19] Rahman, K. (2007) Studies on Free Radicals, Antioxidants, and Co-Factors. Clinical Interventions in Aging, 2, 219236.

[20] Bouzid, M.A., Hammouda, O., Matran, R., Robin, S. and Fabre, C. (2014) Changes in Oxidative Stress Markers and Biological Markers of Muscle Injury with Aging at Rest and in Response to an Exhaustive Exercise. PLoS ONE, 9 , e90420. http://dx.doi.org/10.1371/journal.pone.0090420

[21] Andriollo-Sanchez, M., Hininger-Favier, I., Meunier, N., Venneria, E., O’Connor, J.M., Maiani, G., et al. (2005) Age-Related Oxidative Stress and Antioxidant Parameters in Middle-Aged and Older European Subjects: The ZENITH Study. European Journal of Clinical Nutrition, 59, S58-S62. http://dx.doi.org/10.1038/sj.ejen.1602300

[22] Kennedy, D.O. and Wightman, E.L. (2011) Herbal Extracts and Phytochemicals: Plant Secondary Metabolites and the Enhancement of Human Brain Function. Advances in Nutrition, 2, 32-50. http://dx.doi.org/10.3945/an.110.000117

[23] Le Bars, P.L., Katz, M.M., Berman, N., Itil, T.M., Freedman, A.M. and Schatzberg, A.F. (1997) A Placebo-Controlled, Double-Blind, Randomized Trial of an Extract of Ginkgo biloba for Dementia. JAMA, 278, 1327-1332. http://dx.doi.org/10.1001/jama.1997.03550160047037

[24] Bastianetto, S., Ramassamy, C., Dore, S., Christian, Y., Poirier, J. and Quirion, R. (2000) The Ginkgo biloba Extract (EGb 761) Protects Hippocampal Neurons against Cell Death Induced by Beta-Amyloid. European Journal of Neuroscience, 12, 1882-1890. http://dx.doi.org/10.1046/j.1460-9568.2000.00069.x

[25] Alternative Medicine Review Monographs (Accessed 30 January 2016) Ginkgo biloba. http://www.anaturalhealingcenter.com/documents/Thorne/monos/GinkgoMono.pdf

[26] Kleijnen, J. and Knipschild, P. (1992) Ginkgo biloba. The Lancet, 340, 1136-1139. http://dx.doi.org/10.1016/0140-6736(92)93158-J

[27] Diamond, B.J., Shiflett, S.C., Feiwel, N., Matheis, R.J., Noskin, O., Richards, J.A., et al. (2000) Ginkgo biloba Extract: Mechanisms and Clinical Indications. Archives of Physical Medicine and Rehabilitation, 81, 668-678.

[28] SQUARE Herbal \& Nutraceuticals Ltd. (Accessed 30 January 2016) Giloba. http://www.squarepharma.com.bd/downloads/Giloba.\%20DS.PDF

[29] Hamdard Laboratories (WAQF) Bangladesh (Accessed 30 January 2016) Capsule Kobi®. http://www.hamdard.com.bd/product-detail/capsule-kobi/

[30] Thomford, N.E., Dzobo, K., Chopera, D., Wonkam, A., Skelton, M., Blackhurst, D., et al. (2015) Pharmacogenomics Implications of Using Herbal Medicinal Plants on African Populations in Health Transition. Pharmaceuticals, 8, 637663. http://dx.doi.org/10.3390/ph8030637

[31] Tabish, S.A. (2008) Complementary and Alternative Healthcare: Is It Evidence-Based? International Journal of Health Sciences, 2, 5-9.

[32] Zhang, J., Onakpoya, I.J., Posadzki, P. and Eddouks, M. (2015) The Safety of Herbal Medicine: From Prejudice to Evidence. Evidence-Based Complementary and Alternative Medicine, 2015, Article ID: 316706. http://dx.doi.org/10.1155/2015/316706 
[33] Fakeye, T.O., Adisa, R. and Musa, I.E. (2009) Attitude and Use of Herbal Medicines among Pregnant Women in Nigeria. BMC Complementary and Alternative Medicine, 9, 53. http://dx.doi.org/10.1186/1472-6882-9-53

[34] Chiel, H.J., Ting, L.H., Ekeberg, Ö. and Hartmann, M.J.Z. (2009) The Brain in Its Body: Motor Control and Sensing in a Biomechanical Context. The Journal of Neuroscience, 29, 12807-12814. http://dx.doi.org/10.1523/JNEUROSCI.3338-09.2009

[35] Webb, T.W. and Graziano M.S.A. (2015) The Attention Schema Theory: A Mechanistic Account of Subjective Awareness. Frontiers in Psychology, 6, Article 500.

[36] Lakoff, G. (2014) Mapping the Brain's Metaphor Circuitry: Metaphorical Thought in Everyday Reason. Search Results. Frontiers in Human Neuroscience, 8, Article 958. http://dx.doi.org/10.3389/fnhum.2014.00958

[37] Brown, R.E. and McKenna, J.T. (2015) Turning a Negative into a Positive: Ascending GABAergic Control of Cortical Activation and Arousal. Frontiers in Neurology, 6, Article 135. http://dx.doi.org/10.3389/fneur.2015.00135

[38] Sara, S.J. (2000) Retrieval and Reconsolidation: Toward a Neurobiology of Remembering. Learning \& Memory, 7, 7384. http://dx.doi.org/10.1101/lm.7.2.73

[39] Joan, M. (2007) An Overview of Attention: Behavior and Brain. Journal of Neurologic Physical Therapy, 31, 98-103. http://dx.doi.org/10.1097/NPT.0b013e31814d7874

[40] Shen, L.-H., Liao, M.-H. and Tseng, Y.-C. (2012) Recent Advances in Imaging of Dopaminergic Neurons for Evaluation of Neuropsychiatric Disorders. Journal of Biomedicine and Biotechnology, 2012, Article ID: 259349. http://dx.doi.org/10.1155/2012/259349

[41] Sylwester, R. and Cho, J.-H. (1992) What Brain Research Says about Paying Attention. Educational Leadership, 50, $71-75$.

http://www.ascd.org/publications/educational-leadership/dec92/vol50/num04/What-Brain-Research-Says-About-Payin g-Attention.aspx

[42] Husain, M. and Mehta, M.A. (2011) Cognitive Enhancement by Drugs in Health and Disease. Trends in Cognitive Sciences, 15, 28-36. http://dx.doi.org/10.1016/j.tics.2010.11.002

[43] De Smedt, J. and De Cruz, H. (2010) Toward an Integrative Approach of Cognitive Neuroscientific and Evolutionary Psychological Studies of Art. Evolutionary Psychology, 8, 695-719. http://dx.doi.org/10.1177/147470491000800411

[44] Mashour, G.A. and Alkire, M.T. (2013) Evolution of Consciousness: Phylogeny, Ontogeny, and Emergence from General Anesthesia. Proceedings of the National Academy of Sciences of the United States of America, 110, 1035710364. http://dx.doi.org/10.1073/pnas.1301188110

[45] Lobier, M., Dubois, M. and Valdois, S. (2013) The Role of Visual Processing Speed in Reading Speed Development. PLoS ONE, 8, e58097. http://dx.doi.org/10.1371/journal.pone.0058097

[46] Jensen, G.M., Gwyer, J., Shepard, K.F. and Hack, L.M. (2000) Expert Practice in Physical Therapy. Physical Therapy, 80, 28-41.

[47] Arnett, J.A. and Labovitz, S.S. (1995) Effect of Physical Layout in Performance of the Trail Making Test. Psychological Assessment, 7, 220-221. http://dx.doi.org/10.1037/1040-3590.7.2.220

[48] Mathôt, S., van der Linden, L., Grainger, J. and Vitu, F. (2013) The Pupillary Light Response Reveals the Focus of Covert Visual Attention. PLoS ONE, 8, e78168. http://dx.doi.org/10.1371/journal.pone.0078168

[49] Linton, S.J. and Shaw, W.S. (2011) Impact of Psychological Factors in the Experience of Pain. Physical Therapy, 91, 700-711. http://dx.doi.org/10.2522/ptj.20100330

[50] Posner, M.I., Rothbart, M.K., Sheese, B.E. and Voelker, P. (2014) Developing Attention: Behavioral and Brain Mechanisms. Advances in Neuroscience, 2014, Article ID: 405094. http://dx.doi.org/10.1155/2014/405094

[51] Harris, L.N. and Perfetti, C.A. (2016) Lexical Stress and Linguistic Predictability Influence Proofreading Behavior. Behavior. Frontiers in Psychology, 7, Article 96. http://dx.doi.org/10.3389/fpsyg.2016.00096

[52] Benton, A.L. (1968) Differential Behavioral Effects in Frontal Lobe Disease. Neuropsychologia, 6, 53-60. http://dx.doi.org/10.1016/0028-3932(68)90038-9

[53] Stoet, G., O'Connor, D.B., Conner, M. and Laws, K.R. (2013) Are Women Better than Men at Multi-Tasking? BMC Psychology, 1, 18. http://dx.doi.org/10.1186/2050-7283-1-18 


\section{Abbreviations}

NF: Numeral finding;

TR: Typo revealing;

GBG: Ginkgo biloba standardized extract of Giloba ${ }^{\circledR}$;

GBK: Ginkgo biloba standardized extract of Kobi ${ }^{\circledR}$;

PC: Placebo control;

CNS: Central nervous system;

ADHD: Attention deficit hyperactivity disorder;

AD: Alzheimer's disease;

PD: Parkinson's disease;

LBD: Lewy body dementia;

FTD: Frontotemporal dementia;

SSC: Secondary school certificate;

HSC: Higher secondary certificate;

NFT: Numeral finding time;

IA: Improved attention;

TNCWNs: Total number of correct wanted numerals identified by the subject;

TNPWNs: Total number of presented wanted numerals in the chart;

TFT: Typo finding time;

TNCTs: Total number of correct typos identified by the subject;

TNPTs: Total number of presented typos in the passage.

Submit or recommend next manuscript to SCIRP and we will provide best service for you:

Accepting pre-submission inquiries through Email, Facebook, Linkedin, Twitter, etc A wide selection of journals (inclusive of 9 subjects, more than 200 journals)

Providing a 24-hour high-quality service

User-friendly online submission system

Fair and swift peer-review system

Efficient typesetting and proofreading procedure

Display of the result of downloads and visits, as well as the number of cited articles

Maximum dissemination of your research work

Submit your manuscript at: http://papersubmission.scirp.org/ 